\title{
Identifying barriers to accessing information and treatment for obstetric fistula in Niamey, Niger
}

\author{
Marielle E. Meurice,$^{1}$ Rene R. Genadry, ${ }^{2}$ Catherine S. Bradley, ${ }^{2}$ Benjamin Majors, ${ }^{3}$ \\ Sanda O. Ganda ${ }^{4}$
}

Keywords: Obstetric fistula, barriers to access, barriers to treatment, Niger, urinary incontinence, genitourinary fistula, obstructed labor, maternal health

\begin{abstract}
Objective: To identify barriers to accessing information and treatment regarding obstetric fistula (OF) unique to Niger encountered by women referred to the National Referral Fistula Center.
\end{abstract}

Method: A questionnaire was administered at the National Referral Fistula Center to 29 women with OF. Qualitative and quantitative statistics were computed.

Results: The average individual was 30.4 years old, illiterate and from a rural area. $76.0 \%$ had antenatal care, the average labor time was 3.04 days, and $88.0 \%$ had a physician-assisted delivery. Barriers to information included rural dwelling, lack of education, lack of understanding of cause despite contact with health care workers, lack of knowledgeable resources to seek advice from or lack of ability/interest, not given specific information about availability of treatment, and not utilizing available resources to disseminate information. Barriers to treatment included lack of information regarding condition and treatment, traditional healer utilization, inability to access adequate care for condition, delay for childbirth recovery, permission needed to seek treatment, cost, timely treatment unavailable, and lack of social support.

Conclusion: Improving efficiency of getting women to the hospital at time of delivery, prompt referrals for OF, and using cell phones for disseminating information or accessing transport may benefit women with OF in Niger.

\footnotetext{
${ }^{1}$ University of lowa Carver College of Medicine, lowa City, lowa

${ }^{2}$ University of lowa Hospitals and Clinics, Department of Obstetrics and Gynecology, lowa City, lowa

${ }^{3}$ University of lowa College of Public Health, lowa City, lowa

${ }^{4}$ Lamordé Hospital, Niamey, Niger
}

\section{Introduction}

Women in the developing world who survive an obstructed labor are at risk of

Please cite this paper as: Meurice ME, Genadry RR, Bradley CS, Majors B, Ganda SO. A Identifying barriers to accessing information and treatment for obstetric fistula in Niamey, Niger. Proc Obstet Gynecol. 2016;6(2):1 [ 13 p.]. Available from: http://ir.uiowa.edu/pog/ Free full text article.

Corresponding author: Marielle E. Meurice, University of lowa Carver College of Medicine, lowa City, Iowa. Email: marielle-meurice@uiowa.edu

Financial Disclosure: The authors report no conflict of interest.

Received: 27 January 2016; accepted 28 April 2016; POG in Press, 9 May 2016.

Copyright: (c) 2016 Meurice et al. This is an open-access article distributed under the terms of the Creative Commons Attribution License, which permits unrestricted use, distribution, and reproduction in any medium, provided the original author and source are credited. 
being plagued with an obstetric fistula (OF), a communication between the vagina and the urethra, bladder or rectum. Depending on the location of the fistula, feces and/or urine may leak uncontrollably. ${ }^{1}$ This creates devastating social, medical, and psychological issues that can last a lifetime if uncorrected. This condition is preventable and treatable with surgery, which has led to the near eradication of OF in high-income countries since the early 20th century. ${ }^{2}$ Yet, OF persists in low-income countries, with an estimated prevalence of 1.60 per 1,000 women in Sub-Saharan Africa. $^{3}$ Although many studies have looked at OF in African countries and other areas of the world, few scholarly articles focus on Niger.

Velez et al. 2007 assessed barriers to treatment in countries affected by OF excluding Niger. Access to treatment was hindered by geographic and financial obstacles and was compounded by the paucity of treatment centers with the required specialized care and sufficiently trained staff. ${ }^{4}$ Ndiaye et al. 2009 studied OF in Niger and found the average delay to getting medical help was at least 3 months in $66 \%$ of cases, with "lack of awareness of treatment availability" or "unavailability of transportation" cited as the reasons for the delay. ${ }^{5}$

We hypothesized that women seeking treatment for OF at the Fistula Center in Niamey, Niger face significant barriers to accessing information and treatment, and we elected to assess those barriers in patients that overcame them.

\section{Materials and Methods}

The study was conducted at the National Reference Center for Obstetric Fistula (Centre National de Référence de la Fistule Obstétricale-CNRFO) in Niamey, Niger, which was created in 2008 to provide surgical treatment.

The University of lowa Institutional Review Board and the National Ethics Committee of Niger gave prior approval. Individuals seeking treatment for OF at the CNRFO were included if 18 years or older or under 18 with parental consent. Excluded were patients under 18 without parental consent and those with fistulas due to non-obstetric causes.

A focused questionnaire was administered following a comprehensive informed oral consent. The questionnaire included qualitative and quantitative questions regarding: demographics; obstetric information; access to information about pregnancy, OF, and treatment availability; and other barriers to accessing treatment. Women were asked their opinion on improving access to treatment and information. An interpreter translated English to Hausa and Zarma. The questionnaire was piloted with the interpreter and CNRFO staff.

Data were collected using paper forms and recorded and stored in a Microsoft Excel database, where preliminary statistics were computed. Open-ended responses were grouped by theme and analyzed. Further analysis was generated using the SAS/STAT software (Copyright SAS Institute Inc., Cary, NC, USA). Wilcoxon rank-sum and Fisher's exact tests were used with 
statistical significant at $p<0.05$. Some women were unable to answer all questions, which is reflected in the changing " $n$ " values.
Between July 7-23, 2014, 29 patients participated in the study, following inclusion criteria and oral consent. One individual was excluded due to a fistula from a non-obstetric cause. A flow diagram is outlined in Figure 1.

\section{Results}

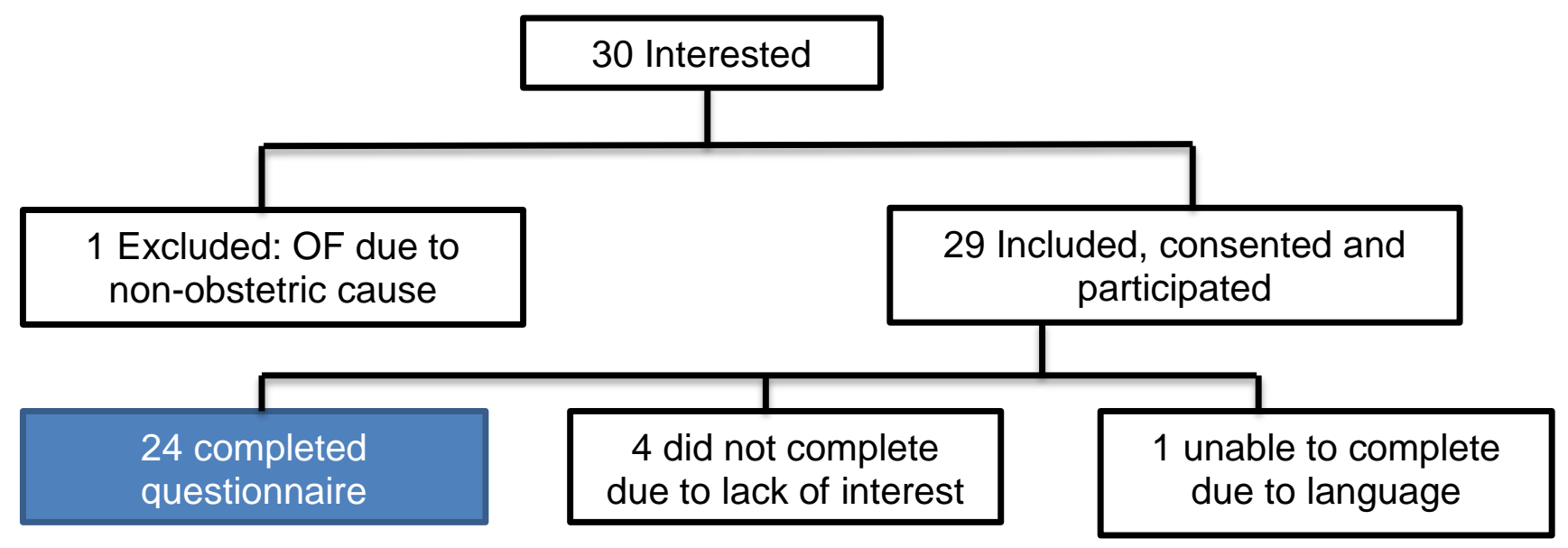

Figure 1: Participation Flow Diagram

Demographic data is summarized in Table 1. All participants were Muslim and 11 ethnic groups were represented, with the majority $(15 / 29,51.7 \%)$ of Zarma ethnicity. The majority (20/28, $71.4 \%)$ of individuals were from the Tillaberi region, where the CNRFO is located.

No one specifically reported being deserted by their husband, but 9 $(36.0 \%, n=25)$ reported leaving their husband since the occurrence of their fistula. The majority (17/25, 68.0\%) reported no change in their marriage status since the occurrence of their fistula. However, only $10(34.5 \%, \mathrm{n}=29)$ reported currently living with her husband. There were 17/25 (93.1\%) whose husband's had other wives. There were 19/24 (79.2\%) women that reported participation in their community changing after the occurrence of their fistula. The average age of first pregnancy was 17.9 years (+/- 2.6, $\mathrm{n}=23)$. There were a high number of stillbirths (average of 1.36 per person, $+/-1.16, \mathrm{n}=28$ ) and a low number of living children (average .89 per person, $+/-1.5, \quad n=28)$. There were $13 / 28$ (46.4\%) patients who had given birth to only 1 child. 
Table 1: Demographic Data

\begin{tabular}{|c|c|}
\hline Characteristic & Value \\
\hline Age & $n=29$ \\
\hline Average age in years (+/- std dev) & $30.4(10.5)$ \\
\hline Minimum & 18.0 \\
\hline Maximum & 51.0 \\
\hline \multicolumn{2}{|l|}{ Living Situation } \\
\hline Lives in a city (\%) & $8(27.6)$ \\
\hline Lives in a rural area (\%) & $21(72.4)$ \\
\hline \multicolumn{2}{|l|}{ Currently living in: } \\
\hline Husband's home (\%) & $10(34.5)$ \\
\hline Parental home (\%) & $14(48.3)$ \\
\hline Relative's home (\%) & $3(10.3)$ \\
\hline CNRFO (\%) & $1(3.5)$ \\
\hline In between homes $(\%)$ & $1(3.5)$ \\
\hline Has an attendant with them at the CNRFO (\%) & $17(58.6)$ \\
\hline \multicolumn{2}{|l|}{ Education/Financial } \\
\hline Has attended primary school (\%) & $5(17.2)$ \\
\hline Never attended school (\%) & $24(82.8)$ \\
\hline Cannot read at all (\%) & $25(86.2)$ \\
\hline Can read with difficulty (\%) & $4(13.8)$ \\
\hline \multicolumn{2}{|l|}{ Primary source of financial support: } \\
\hline Husband (\%) & $13(44.8)$ \\
\hline Self $(\%)$ & $4(13.8)$ \\
\hline Parents (\%) & $4(13.8)$ \\
\hline Other relatives/combination of relatives (\%) & $7(24.1)$ \\
\hline No one (\%) & $1(3.5)$ \\
\hline \multicolumn{2}{|l|}{ Marital Status } \\
\hline Married (\%) & $17(58.6)$ \\
\hline Divorced (\%) & $3(10.3)$ \\
\hline Separated (\%) & $7(24.1)$ \\
\hline \multirow[t]{2}{*}{ Subject left husband (\%) } & $2(6.9)$ \\
\hline & $\mathrm{n}=25$ \\
\hline Average age of first marriage (+/-std dev) & $16.2(3.0)$ \\
\hline \multirow[t]{2}{*}{ Husband has other wives (\%) } & $17(93.1)$ \\
\hline & $n=29$ \\
\hline Marriage has not changed since occurrence of fistula & $17(58.6)$ \\
\hline Husband divorced study subject since the occurrence of fistula & $2(6.9)$ \\
\hline Study subject left her husband since the occurrence of fistula & $9(31.0)$ \\
\hline Parity & $\mathrm{n}=23$ \\
\hline \multirow[t]{2}{*}{ Average age of first pregnancy in yrs (+/- std dev) } & $17.9(2.6)$ \\
\hline & $\mathrm{n}=28$ \\
\hline Average number of children birthed (+/- std dev) & $2.6(2.3)$ \\
\hline Average number of stillbirths (+/- std dev) & $1.4(1.2)$ \\
\hline \multirow[t]{2}{*}{ Average number of living children (+/- std dev) } & $.9(1.5)$ \\
\hline & $n=26$ \\
\hline No prior history of contraceptive use (\%) & $22(84.6)$ \\
\hline History of female circumcision (\%) & $2(7.7)$ \\
\hline
\end{tabular}


Table 2: Index Pregnancy Data

\begin{tabular}{|c|c|}
\hline Characteristic & Value \\
\hline Antenatal Care (ANC) & $\mathrm{n}=25$ \\
\hline \multirow[t]{2}{*}{ Received ANC (\%) } & $19(76.0)$ \\
\hline & $\mathrm{n}=19$ \\
\hline \multirow{3}{*}{ Told about importance of having a birth plan prior to delivery (\%) } & $3.8(1.0)$ \\
\hline & $5(26.3)$ \\
\hline & $\mathrm{n}=25$ \\
\hline Had a birth plan prior to delivery (\%) & $6(24.0)$ \\
\hline \multicolumn{2}{|l|}{ Delivery Information } \\
\hline Assisted by doctor during delivery (\%) & $22(88.0)$ \\
\hline \multicolumn{2}{|l|}{ Location of delivery: } \\
\hline Hospital or Health Center (\%) & $21(84.0)$ \\
\hline Home (\%) & $3(12.0)$ \\
\hline On way to facility (\%) & $1(4.0)$ \\
\hline Length of time in labor (days) & $\mathrm{n}=21$ \\
\hline Average (+/- std dev) & $3.0(2.4)$ \\
\hline \multirow{6}{*}{$\begin{array}{r}\text { Vaginal, normal (\%) } \\
\text { Vaginal, forceps (\%) } \\
\text { Caesarian section (\%) } \\
\text { Doesn't know (\%) }\end{array}$} & $\mathrm{n}=25$ \\
\hline & $10(40.0)$ \\
\hline & $2(8.0)$ \\
\hline & $12(48.0)$ \\
\hline & $1(4.0)$ \\
\hline & \\
\hline Developed pregnancy complications during delivery (\%) & $23(92.0)$ \\
\hline Sought medical care for complications during delivery: & $\mathrm{n}=23$ \\
\hline Yes & 21 \\
\hline \multirow[t]{2}{*}{ No (both responded that hospital was too far) } & 2 \\
\hline & $n=24$ \\
\hline \multirow[b]{2}{*}{ For those who delivered in a hospital/clinic } & $22(91.7)$ \\
\hline & $n=21$ \\
\hline Median length of time spent in hospital after delivery in days & 14 \\
\hline \multirow[t]{2}{*}{ Catheter used (\%) } & $16(76.2)$ \\
\hline & $\mathrm{n}=24$ \\
\hline Subjects that had questions regarding childbirth during pregnancy (\%) & $4(16.7)$ \\
\hline Persons asked these questions: & $\mathrm{n}=4$ \\
\hline No one (\%) & $3(75.0)$ \\
\hline Elder sister (\%) & $1(25.0)$ \\
\hline
\end{tabular}


Table 2 summarizes the information regarding the birth that resulted in OF. The majority $(19 / 25,76.0 \%)$ received antenatal care (ANC), with an average of 3.8 visits $(+/-1.0, n=19)$. Despite ANC, few (5/19, 26.3\%) had been told about the importance of a birth plan and only 6 had one prior to delivery $(24.0 \%$, $\mathrm{n}=25$ ). However, most individuals $(22 / 25,88.0 \%)$ had a physician-assisted delivery. Additionally of those 22, 17 (77.3\%) reported a family member also assisting-- usually a mother or other female relative. The labor length was an average of 3.0 days $(+/-2.4, \mathrm{n}=21)$, as reported from the start of labor until birth. Subjects were asked to estimate the time at home, in transit, and in the hospital but so many had difficulty estimating these individual components that the responses were not included.
There were 12 caesarean sections amongst the cohort $(48.0 \%, \mathrm{n}=25)$. Almost all participants (22/24, 91.7\%) had stillbirths. After the delivery, the median length of stay at a facility was 14 days $(n=21)$.

Of the 4 subjects who did not deliver in a hospital, 1 (25.0\%) received ANC, none had a birth plan, and none delivered with a qualified professional. The average labor length for this subset was $4.5+/$ - 3.0 days. All the births were vaginal stillbirths. One individual did not attempt to go to the hospital.

Table 3 details data regarding the fistula. The median interval was 3.0 days $(n=24)$ from giving birth to starting leaking urine and/or feces and the median number of years leaking was 3.0 $(n=23)$.

\section{Table 3: Fistula Data}

\begin{tabular}{|c|c|c|}
\hline Category & & Value \\
\hline \multirow[t]{2}{*}{ Days after giving birth when started to leak continuously (days): } & & $\mathrm{n}=24$ \\
\hline & Median & 3.0 \\
\hline \multicolumn{3}{|l|}{ Leaking/leaked: } \\
\hline & Urine (\%) & $22(91.7)$ \\
\hline & Feces $(\%)$ & $1(4.2)$ \\
\hline & Feces and Urine (\%) & $1(4.2)$ \\
\hline \multirow[t]{2}{*}{ Length of time since leaking started (years): } & & $\mathrm{n}=23$ \\
\hline & Median & 3.0 \\
\hline \multicolumn{3}{|l|}{ Pregnancy Since Occurrence of Fistula } \\
\hline Has been pregnant since occurrence of fistula(\%) & & $5(20.8)$ \\
\hline \multirow{2}{*}{ Pregnancy outcome: } & & $\mathrm{n}=5$ \\
\hline & gnancies (+/- std dev) & $3.4(3.1)$ \\
\hline
\end{tabular}

Figure 2 compares age and years leaking urine and/or feces. The positive correlation indicates that most individuals acquire OF while young and many suffer for years. The average age of acquiring OF was estimated to be 
22.1 years $(+/-5.6, n=23)$. There were 5 individuals $(20.8 \%, \mathrm{n}=24)$ that had been pregnant since acquiring their fistula. The questionnaire did not capture whether they had been treated and had a recurrence, however they all had surgery for fistula prior to the studyand $4 / 5(80.0 \%)$ had 3 or more surgeries. The trend was that those who had been pregnant since acquiring a fistula had more surgeries than those who had not (Wilcoxon rank-sum statistic: $63.0, p$ value $=0.12$ ), though this was not statistically significant.

The patients' responses identified important barriers to accessing information regarding their condition. Barriers to accessing information are confirmed by 11 individuals $(45.8 \%$, $\mathrm{n}=24$ ) reported no understanding of the cause of OF. Additionally there were only 7 individuals $(29.1 \%, \mathrm{n}=24)$ who reported ever being given any information from anyone regarding the cause. These barriers are summarized in Table 4 and include:

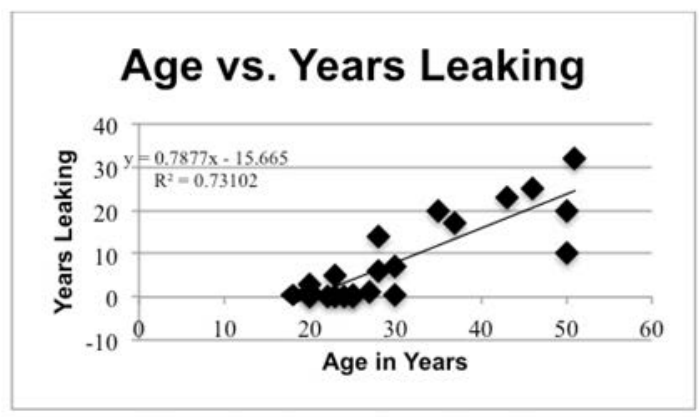

Figure 2: Age vs. Years Leaking

\section{Table 4: Barriers to Information}

Barriers to Information
1. Rural dwelling
2. Lack of education
3. Lack of understanding of cause despite contact with health care worker
4. Lack of knowledgeable resources to seek advice from or lack of ability/interest in seeking advice
5. Not given specific information about where treatment is available
6. Not utilizing available resources to disseminate information

1. Rural dwelling. Although the majority of patients were from the region around the capital, most hailed from rural areas: 21/29 (72.4\%).

2. Lack of Education. $82.8 \%$ of patients (24/29) never attended primary school and $86.2 \%$ (25/29) were illiterate. $72.4 \%$ $(21 / 29)$ of husbands never attended school.

3. Lack of understanding of cause despite contact with health care workers (HCW). A high percentage received ANC $(19 / 25,76.0 \%)$, delivered in hospitals or health centers (21/25, $84.0 \%)$, and stayed at the delivery location postpartum (median= 14 days, $n=21$ ) without education.

4. Lack of knowledgeable resources to seek advice from or lack of ability/interest in seeking advice. Few women $(4 / 24,16.7 \%)$ reported having 
questions regarding childbirth during the index pregnancy, and only 1 sought answers (25.0\%). 11 individuals (45.8\%, $\mathrm{n}=24$ ) had unanswered questions regarding the cause of their fistula. While 10/24 (41.7\%) sought advice from no one, only $3 / 24(12.5 \%)$ reported seeking advice from a HCW.

5. Not given specific information about where treatment is available. The location for treatment within Niamey has evolved over time. It was common for women $(11 / 24,45.8 \%)$ to be told generally to go to Niamey or to another hospital in Niamey that no longer provided treatment.

6. Not utilizing available resources to disseminate information. Twenty of 24 (83.3\%) individuals had access to cell phones and 14/24 (58.3\%) to radios. Cell phones were reported most frequently as the best way to receive information (15/24, 62.5\%). No patient reported learning information regarding OF through cell phone, but 4/24 (16.7\%) did via the radio. Figure 3 details the access to resources at time of study. Another potential resource that patients mentioned $(5 / 13,38.5 \%)$ was having treated women teach others about OF.

A number of barriers to accessing treatment are recognized, as exhibited by a median of 3 years of leaking $(\mathrm{n}=23)$. Additionally,12 individuals $(50.0 \%, \quad n=24)$ reported wanting to access medical care for their condition but were unable to do so. There is obvious overlap with barriers to accessing information be it regarding condition or treatment thereof, but some unique features are outlined in Table 5, including:

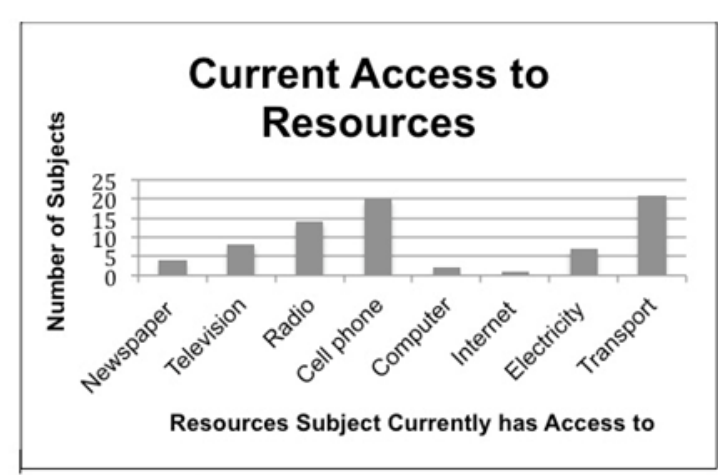

Figure 3: Access to Resources in place where individual currently lives

1. Lack of information regarding condition and treatment. Only 2/24 (8.3\%) reported learning about treatment availability at the time of the index birth, even though many started to leak while hospitalized or when discharged. Once women learned about treatment at the CNRFO, the majority $(14 / 24,58.3 \%)$ left immediately. Women sought care at an average of 1.5 locations $(+/-1.0, n=24)$ outside of the CNRFO.

2. Traditional healer utilization. Of the 3 individuals who utilized traditional healers, 2 delivered at home (66.7\%). Comparing these 3 versus 19 that delivered at a facility, those who delivered at a facility were significantly less likely to have received traditional treatment for OF (Fisher's Exact $p$ value, 0.03).

3. Inability to access adequate care for condition. Of the 24 responses, only 5 individuals $(20.8 \%)$ had not received surgery for OF. Often subjects visited other health care facilities prior to the CNRFO for treatment (20/24, 83.3\%) and $4 / 12(33.3 \%)$ could not find care at 
the health care facility where initially referred.

4. Delay for recovery from childbirth. $13 / 24$ (54.2\%) individuals wanted to seek treatment earlier than they did. Of these, individuals, 5 (38.5\%) were told to recover at home from childbirth before seeking treatment-4 (80.0\%) mentioned specifically 3 months.

5. Permission needed to seek treatment. $5 / 24(20.8 \%)$ needed permission prior to seeking treatment. Permission was most often sought from male relatives.

6. Cost of travel and treatment. Prior treatment was free for $17 / 19$ (89.5\%) individuals. However, patients still needed money for food and transportation. In most cases (17/21, $81.0 \%)$ the family provided the money.
There were 5/18 (27.8\%) that reported that providing transportation or transportation fees would have made accessing treatment easier, and 19/24 $(79.2 \%)$ had to save money prior to coming to the CNRFO.

7. Timely treatment not available at the CNRFO or other locations. 8/21 (38.1\%) reported that treatment was made difficult by waiting and lack of available treatment.

8. Lack of social support. 17/29 (58.6\%) had an attendant at the CNRFO. Five patients $(17.2 \%, n=29)$ were their own primary source of financial support. Although there were no patients reporting abandonment by their husbands, 9/25 (36.0\%) left their husband.

\section{Table 5: Barriers to Treatment}

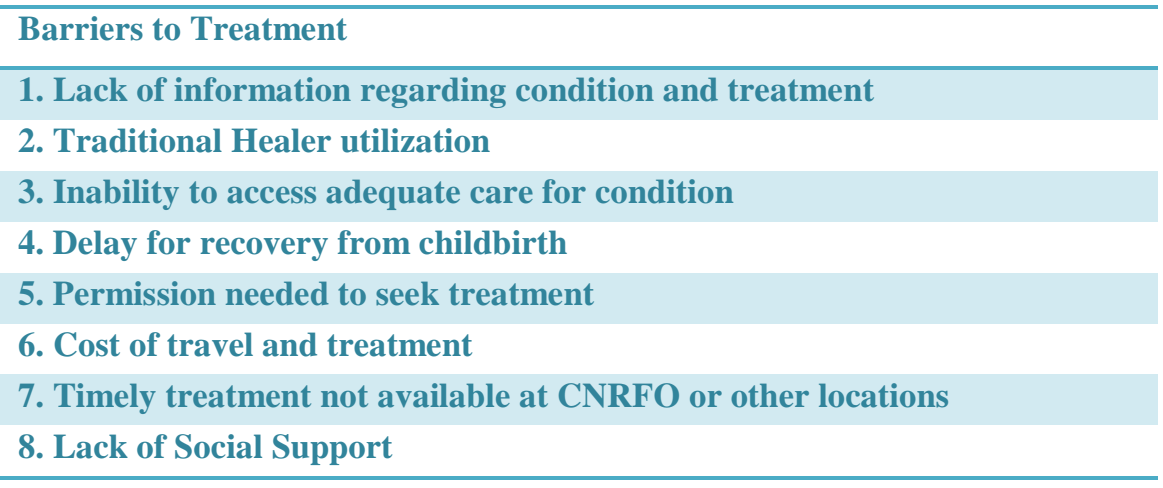

\section{Discussion}

The study results provide insight into potential ways to eliminate some of the barriers encountered by those seeking treatment for OF. These barriers start with lack of information regarding the condition and its treatment as well as the inability to access proper treatment centers when such information is obtained. These barriers are equally environmental, social, economic and physical. The study involved those patients that were able to overcome many of these obstacles and were able to identify them. Generally, women were 
about 30 years old, illiterate, from a rural area, and had access to medical care but endured a long labor. Notably there were more individuals than anticipated from cities (8/29, 27.6\%). Those from cities were more likely to be literate than those from a rural area (Fisher's exact p-value $=0.05$ ).

Women had more contact with HCW than foreseen-during pregnancy, postpartum, and when seeking treatment. Despite these interactions, women were not well-informed about the cause of OF. These "missed opportunities" provide potential for an intervention to better identify those at risk for OF and referring those affected. Further research and prevention of these "missed opportunities" has the potential to profoundly help women at risk or already suffering from OF. It may also be more feasible and efficient to target improvement at the level of HCW's, as it is an educated, smaller group of people that likely come into contact with many women. Ameliorating this lack of adequate communication or lack of adequately trained staff could address multiple barriers related to both access to information and treatment.

Women in this cohort generally received ANC and eventually delivered in a health facility in an untimely and less than optimal fashion. Aspects of this delay may be difficult to identify and improve upon in the short term, especially if related to infrastructure (e.g. road conditions, hospital locations) and resource availability (e.g. staff trained for cesarean sections, physician or HCW density in rural areas), but nonetheless an important aspect of OF. Indeed the high rate of cesarean section after fetal death has occurred begs the question of alternative modes of delivery following the occurrence of fetal demise. These carry their own risk of injury while timely access to proper care would hopefully reduce the rate of fetal death and minimize their indication.

For this population, proper antenatal care is an incredible opportunity to assess women for risk obstructed labor as well as educate them on the importance of timely arrival to the hospital, on potential problems that may be encountered during labor, and on where to seek care. Furthermore, the training of HCW and hospital staff in managing obstructed labor and its consequences is critical if patients were to benefit from their timely access to care. ANC measurements of the intertuberous space has been proposed as simple screening tool to predict those at a higher risk for developing OF. ${ }^{6}$ Perhaps with some training, this method could be employed in Niger. Avoiding delay in getting to a facility where emergency care is available has been studied in Niger by Seim et al. 2014. Using community mobilization, they effectively prevented OF without requiring large-scale changes. ${ }^{7}$

Most women stayed at a facility after giving birth, but their fistula was rarely addressed postpartum. Once patients have reached the hospital, further training for staff on consequences of obstructed labor and risk factors for OF may help with prevention and management of OF. Without adequate resources or staff at the facility this may be easier said than done. Waaldijk et al. 2004 found immediate management was effective and prevented 
psychosocial effects of OF. ${ }^{8}$ Perhaps rather than sending women home to recover, they could be referred immediately to minimize delay and need for funds for transportation. Many women in our study were catheterized post-partum, which may indicate a failed attempt at initial conservation management. Immediate bladder catheterization has been shown to be curative for up to $20 \%$ of fistula patients if done 4-6 weeks postpartum. ${ }^{8,9}$ This management could be incorporated into a standard protocol and would likely require further education for postpartum staff on awareness of OF and indications for referrals to an appropriate facility that can perform surgery.

This study captured a high number of individuals with access to cellphones. Another study with a cohort from Niger found $67.7 \%$ of individuals with household possession of a cell phonemuch higher than other countries surveyed. ${ }^{10}$ Cell phones could provide information and even options for providing transportation, as has been successfully implemented in Tanzania using mobile banking. ${ }^{11}$ Information transfer would require design for illiteracy, perhaps through pre-recorded voice messages or free help-lines.

Lack of education is an important barrier to accessing information and treatment. The CNRFO has staff hired for education, but this is difficult in practice with the low literacy rate. Our data suggests most women had not been educated about OF, and only 3/24 $(12.5 \%)$ reported learning about the cause of OF from the CNRFO. Several women expressed interest in being educated in order to return to their village and teach others; $8 / 24$ (33.3\%) reported knowing another person in their village affected by OF.

While prevention remains a priority for future large-scale initiatives for eradicating OF, valuable research and interventions are still needed to improve the experience of those suffering from OF. Surgical repair remains presently the mainstay of treatment. ${ }^{12}$

This study derives strength from the diversity of ethnicities and direct capture of the accounts of women who have overcome the barriers to accessing information and treatment. Subjects were given time to thoughtfully describe their experience. However, there are also limitations to this study. Working cross-culturally through a translator with low-literacy individuals made numerical estimations difficult. Additionally, the small sample size may not be representative: this is a select group of resourceful patients that found treatment and over two thirds of the patients hailed from the Tillaberi region, whose geography makes the CNRFO more accessible. Barriers experienced by women unable to reach the referral center may be more difficult to overcome, suggesting that decentralization of preventive and therapeutic approaches is necessary-although the level of complexity of their clinical condition was not determined in this encounter.

\section{Conclusion}

In conclusion, this study is a preliminary analysis of the barriers to accessing information and treatment in patients that overcame them. Further studies 
must be done to fully evaluate and address the various components of this complex issue. In the meantime, efficiently getting women to the hospital early when labor is not normal, properly training of $\mathrm{HCW}$ for better delivery of antenatal/peri-partum care and promptly referring patients at risk for acquiring $\mathrm{OF}$, and using cell phones as a resource for information and referral may help women similar to those seeking treatment for OF in Niger.

Acknowledgements Financial sources for this project were from the University of lowa Carver College of Medicine Global Programs Niger Partnership Project, Kenneth J. Cmiel Human Rights Funded Internship Program, Arnold P. Gold Foundation Student Summer Fellowship Program, and Sara's Wish Foundation Scholarship.

\section{References}

1. United Nations Population Fund (UNPFA) \& EngenderHealth (2003).Obstetric fistula needs assessment report: findings from nine African countries. New York; 2003. Available from: http://www.unfpa.org/sites/default/files/p ub-pdf/fistula-needs-assessment.pdf

2. Narcisi L, Tieniber A, Andriani L, McKinney $T$. The fistula crisis in subSaharan Africa: an ongoing struggle in education and awareness. Urol Nurs. 2010 Nov-Dec;30(6):341-6. PubMed PMID: 21261194.

3. Adler AJ, Ronsmans C, Calvert C, Filippi $\mathrm{V}$. Estimating the prevalence of obstetric fistula: a systematic review and meta-analysis. BMC Pregnancy Childbirth. 2013 Dec 30;13:246. http://dx.doi.org/10.1186/1471-2393-13246 PubMed PMID: 24373152.
4. Velez A, Ramsey K, Tell K. The Campaign to End Fistula: what have we learned? Findings of facility and community needs assessments. Int J Gynaecol Obstet. 2007 Nov;99 Suppl 1:S143-50. Epub 2007 Sep 18. http://dx.doi.org/10.1016/j.ijgo.2007.06.0 36 PubMed PMID: 17880980.

5. Ndiaye P, Amoul Kini G, Abdoulaye I, Diagne Camara $M$, Tal-Día A. [Epidemiology of women suffering from obstetric fistula in Niger]. Med Trop (Mars). 2009 Feb;69(1):61-5. French. PubMed PMID: 19499737.

6. Seim AR, Alassoum Z, Bronzan RN, Mainassara AA, Jacobsen JL, Gali YA. Pilot community-mobilization program reduces maternal and perinatal mortality and prevents obstetric fistula in Niger. Int J Gynaecol Obstet. 2014 Dec;127(3):269-74. http://dx.doi.org/10.1016/j.ijgo.2014.06.0 16 Epub 2014 Jul 31. PubMed PMID: 25128929.

7. Browning $A$, Lewis $A$, Whiteside $S$. Predicting women at risk for developing obstetric fistula: a fistula index? An observational study comparison of two cohorts. BJOG. 2014 Apr;121(5):604-9. http://dx.doi.org/10.1111/14710528.12527 Epub 2014 Jan 10. PubMed PMID: 24405643.

8. Waaldijk K. The immediate management of fresh obstetric fistulas. Am J Obstet Gynecol. 2004 Sep;191(3):795-9. http://dx.doi.org/10.1016/j.ajog.2004.02. 020 PubMed PMID: 15467543.

9. Waaldijk K. Immediate indwelling bladder catheterization at postpartum urine leakage--personal experience of 1200 patients. Trop Doct. 1997 Oct;27(4):227-8. PubMed PMID: 9316367. 
10. Landry E, Frajzyngier $V$, Ruminjo J, Asiimwe $F$, Barry TH, Bello A, Danladi $D$, Ganda SO, Idris S, Inoussa M, Kanoma B, Lynch M, Mussell F, Podder DC, Wali A, Mielke E, Barone MA. Profiles and experiences of women undergoing genital fistula repair: findings from five countries. Glob Public Health. 2013;8(8):926-42.

http://dx.doi.org/10.1080/17441692.201 3.824018 Epub 2013 Aug 16. PubMed PMID: 23947903.

11. Fiander A, Ndahani C, Mmuya K, Vanneste T. Results from 2011 for the transportMYpatient program for overcoming transport costs among women seeking treatment for obstetric fistula in Tanzania. Int $\mathrm{J}$ Gynaecol Obstet. $2013 \quad$ Mar;120(3):292-5. http://dx.doi.org/10.1016/j.ijgo.2012.09.0 26 Epub 2012 Dec 22. PubMed PMID: 23265834.

12. Capes T, Ascher-Walsh C, Abdoulaye I, Brodman M. Obstetric fistula in low and middle income countries. Mt Sinai J Med. 2011 May-Jun;78(3):352-61. http://dx.doi.org/10.1002/msj.20265 PubMed PMID: 21598262. 